\title{
A multi-objective optimization-based model for the deployment of reclosers and remote-controlled switches using NSGA2 and entropy weighted TOPSIS method
}

\author{
A. Lekbich ${ }^{1}$, A. Belfqih ${ }^{2}$, T. Ouderhman ${ }^{3}$, C. Zedak $^{4}$, J. Boukherouaa $^{5}$, F. Elmariami ${ }^{6}$ \\ ${ }_{1,2,4,5,6}$ Department of Electrical Networks and Static Converters, National School of Electricity and Mechanics, \\ ENSEM-Hassan II University of Casablanca, Morocco \\ ${ }^{3}$ LS3M Laboratory, FPK, USMS, Morocco
}

\section{Article Info}

Article history:

Received Feb 1, 2020

Revised May 4, 2020

Accepted Jun 7, 2020

\section{Keywords:}

Electrical distribution networks Multi-objective optimization NSGA-II

Reclosers

Reliability indices

Remote-controlled switches

SAIDI

SAIFI

Smart-grid

TOPSIS

\begin{abstract}
Since they are fast, remote-controlled, automated and intelligent, reclosers and switches are an inevitable solution for improving the reliability of intelligent electrical distribution networks at optimal cost. However, their location and coordination have great effects on the protection and automation strategies of complex electrical distribution networks against multiple unpredictable faults. Which requires a flexible and multi-criteria optimization method. In this article, we propose a multi-objective method based on an analytical model by considering the fault rate, restoration times, outage cost and coordination between devices. The non-dominated genetic sorting algorithm II was proposed to obtain the optimal Pareto solutions, and a technique of performance control by similarity with the ideal solution was used to classify them. The objective criteria weights are based on the entropy method which allows solutions to be obtained and better classified with the minimum of subjectivity. The IEEE33 and IEEE13 bus test networks were used to verify the method. The results obtained are compared to a binary multi-objective particle swarm optimization method and the results show that the proposed method reduces the overall costs, reduces the undelivered energy of the system and improves the reliability of the service.
\end{abstract}

Corresponding Author:

Anass Lekbich,

Energy and Electrical Systems laboratory,

El Jadida Road, km 7, BP: 8118, Oasis - Casablanca Morocco.

Email: anass.lekbich@gmail.com

\section{INTRODUCTION}

In recent years, the digitalization of electrical networks has become a reality through the transformation of traditional electrical systems into intelligent and connected networks of devices, paving the way for an environmentally friendly, reliable and smart power system [1]. This situation is favored by several challenges, firstly climate change and environmental obligations require the control of $\mathrm{CO} 2$ emissions by improving reliability and minimizing energy losses. The second obligation is the unpredictable nature of electrical faults in distribution networks and the use of smart devices to reduce outages which will improve reliability and reduce the global cost of energy, particularly in the presence of competition between the various players in the energy distribution sectors. It is therefore necessary to find a tool able of assessing the progress made in terms of reliability and improving the quality of service at a minimum price [2].

Meeting these objectives begins with the choice of the right devices. The use of reclosers and remote-controlled switches is of great interest that can be provided to distribution networks. These devices support several communication protocols using a secure Internet of Things architecture between the control 
center and devices [3-6], operate in decentralized and centralized mode [7], and finally have the capacity to manage outages [8]. All electrical networks have a recloser on the main line to detect electrical faults, isolate the faulted area and coordinate with switches and other devices to resolve all network problems in the shortest time.

The optimal location of reclosers and switches at strategic points considering automation strategies and coordination of communication between equipment is very important and the first step to build a smart energy management system [2]. These new tools give utilities the opportunity to optimize the reliability of electrical distribution networks, which prevents a fault from spreading in the distribution system for a long period of time, reducing the time required to locate this fault and restore the system [9]. The importance of this subject in the engineering of intelligent electrical distribution systems has prompted researchers to develop mathematical models to describe the new functioning of electrical networks in the presence of new automation techniques, devices type and location.

There are two essential parameters impacting the reliability of electrical networks; the fault rate and the time for elimination of faults by the protection system [2]. These parameters can be minimized depending on the structure and topology of the distribution system [1-6]. Various algorithms and mathematical models have been used for reliability enhancement using the optimal placement of reclosers and remote-controlled switches based on two approaches to evaluate these indices, the first method is based on the Monte Carlo simulation method that simulate the behavior of the electrical network facing a multiple location of fault and Equipment [10]. This method consumes computation time and makes the task of planning the network very complex. The second are the analytical model [2] to evaluate the reliability indices. To resolve this problem, many papers use heuristic algorithms such as ant colony algorithms [11] and particle swarm optimization algorithms [12]. In addition to these meta-heuristic algorithms, mathematical optimization models in the manner of mixed integer programming have been introduced by several works [13]. The paper [14] presents an approach based on mixed binary linear programming (MILP) to determine the optimal number, type and location of different types of devices (remote-controlled circuit breakers/reclosers) taking into account the devices cost. The mathematical model proposes automation scenarios minimizing costs and respecting the SAIDI, SAIFI, MAIFI and ASIDI reliability indices. In [15], a multi-objective model is proposed to optimize the reliability and location of equipment (switches or reclosers). For example, by installing switches, SAIDI and SAIFI can be minimized respectively and at minimal cost [15]. The paper [16] tackles the subject of reclosers and switches location based on a cost/benefit analysis methodology in order to minimize the cost of reliability. The optimization method is based on a hybrid solution using the IPSO method (Improved Particle Swarm Optimization) and Monte Carlo simulation. The results of this work show that in an electrical network of 50 buses, the value of the two indicators SAIFI and SAIDI is reduced and the undistributed energy is minimized according to the increase in the number of remote-controlled switches. In addition, the installation of reclosers influences the interruption rate which also minimizes the MAIFI. Article [17] also presents a multi-objective optimization methodology for the optimal location of switches and reclosers by putting the mathematical relationship between the location and the SAIDI and SAIFI reliability indices. In addition, the multi objective model takes into account the undistributed energy for the calculation of the cost function. For resolution, ant colonies (MACO) were applied to this problem. The results of this work show that the addition and displacement of switches and protection devices results in a reduction of the SAIFI and SAIDI indices by approximately $52.03 \%$ and $52.74 \%$ respectively. It is noted for this type of problem, many work tries to evaluate the indices according to the location and the type of equipment as well as propose mathematical resolution model which can be multi-objective or single-objective with weights. Consequently, some researchers have attempted to propose models and algorithms to solve problems on the electrical network by using meta-heuristic methods, decision support tools and adapted economic functions to judge invisibility [18-21].

Although the reviewed literature provided effective approaches to solve the deployment problem, none of the articles considered decision-making issues after determining the optimal solution in depth. Many works also focus on the benefit of installation by optimizing the problem in mono-objective form and the time calculation when the Monte-Carlo simulation is used to evaluate reliability indices. To fill this gap, this paper first establishes a formulation of reliability indices based on an analytical model considering the coordination between protective and controlled devices. This model respects the operation constraint, limitation number to make the method more flexible and adapted to reel complex networks. In a second step, this paper uses a method mixing NSGA2 and entropy-TOPSIS to find an optimal set of Pareto in 3 dimensions, including the locations of several types of protection devices. The entropy weighting method gives us the possibility of detecting intrinsic information and determining the weight of objectives without subjectivity, which improves the results of decision-making by TOPSIS and gives the most suitable scenario without subjectivity. The proposed method has been implemented for IEEE 33 and IEEE 13 bus systems and the results are presented in the last section of the paper. The paper is divided into 4 parts; the first is the 
introduction, the second part describes the method used to obtain the results, part 3 includes the simulation and the results. Finally, the last part contains a conclusion.

\section{RESEARCH METHODOLOGY}

\subsection{Problem Formulation}

The main idea of this work is to reduce the outage time and the number of customers affected by the electrical fault. In reality, to reduce this number, the electrical system must be subdivided into several zones in order to be able to replenish the healthy zones by simply isolating the parts under default. Making the right decisions in smart grids using the latest advanced products is not easy, as the number of scenarios is exponential and the reliability indices strongly depend on many stochastic parameters which make the problem an NP-hard optimization problem. The decision variables are the number and type of electrical devices. The problem must also respect real constraints such as architecture constraints, coordination constraints between equipment, functional constraints, financial limitations, etc.

In this study, we will optimize several parameters. The mathematical model for the formulation of reliability indicators is based on an analytical model [22] which takes into account the coordination between field equipment and the automation strategy to be applied for radial networks.

\subsubsection{The Reliability Indices of The Electrical Distribution Networks}

Reliability indices in electrical networks are a good element to judge the progress during the life of the electrical networks, the most commonly used by public services are described in the IEEE 1366 standard"Guide to reliability indices for electrical energy distribution" [17]. This standard recommends, among other indexes, for long interruptions, the SAIDI index (average system interruption duration index) and the SAIFI index (average system interruption frequency index) for prolonged or long interruptions [23].

These system reliability indicators basically use three main indices; failure rate (or frequency) $\lambda_{s}$, average failure time $r_{s}$, and annual failure time $U_{s}$ [24]. The fault rate is an indicator that measures the frequency of a fault in a given area of the network. The repair time represents the time necessary for the fault to be eliminated. The annual failure time is given by the product of the annual fault rate and the restoration time [25]. Mathematically, these indices are written as follows:

$$
\lambda_{s}=\sum_{j=1}^{N j} \lambda_{j}, U_{s}=\sum_{j=1}^{N j} \lambda_{j} r_{j}, r_{s}=\frac{U_{s}}{\lambda_{s}}
$$

Usually, the distribution system is a complex system, composed of serial and parallel subsystems. For a serial system, the unavailability of electrical energy at the point of consumption can be assessed by Figure 1 [22]:

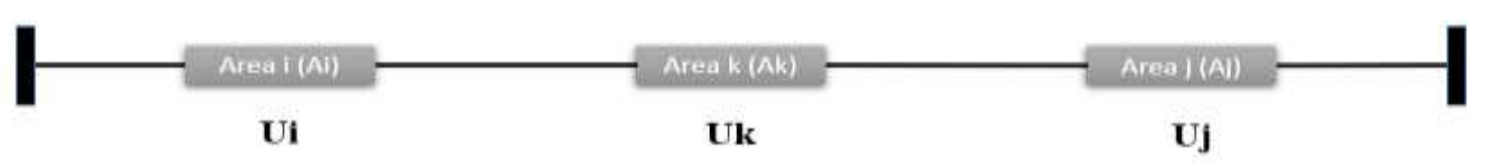

\section{$\mathbf{U}=\mathbf{U} \mathbf{i}+\mathbf{U} \mathbf{k}+\mathbf{U} \mathbf{i}$}

Figure 1. Reliability of a serial system

For a parallel system, a power fault will be perceived by consumption when parallel systems supplying this consumption point are faulty. The formula for unavailability will be given by the following relationship:

$$
U S=\bigcap_{i=1}^{N i} U i
$$

From these basic indices, the system reliability indicators are calculated.

\subsubsection{Operation Philosophy of Distribution Networks}

The process of operating the electrical network in the presence of permanent electrical disturbance is explained in Figure 2 respecting the following steps:

Step 1: normal network 
Step 2: During this step, the recloser performs the opening / closing cycles to isolate the transient fault. If the fault is permanent, this cycle is repeated 3 times to allow the switch to detect the permanent fault.

Step 3: During the last cycle (in the third trip), the downstream switch isolates the upstream area and keep this area energized, this coordination between the recloser and remote-controlled switch isolate the faulty area automatically. This time is the time of isolation.

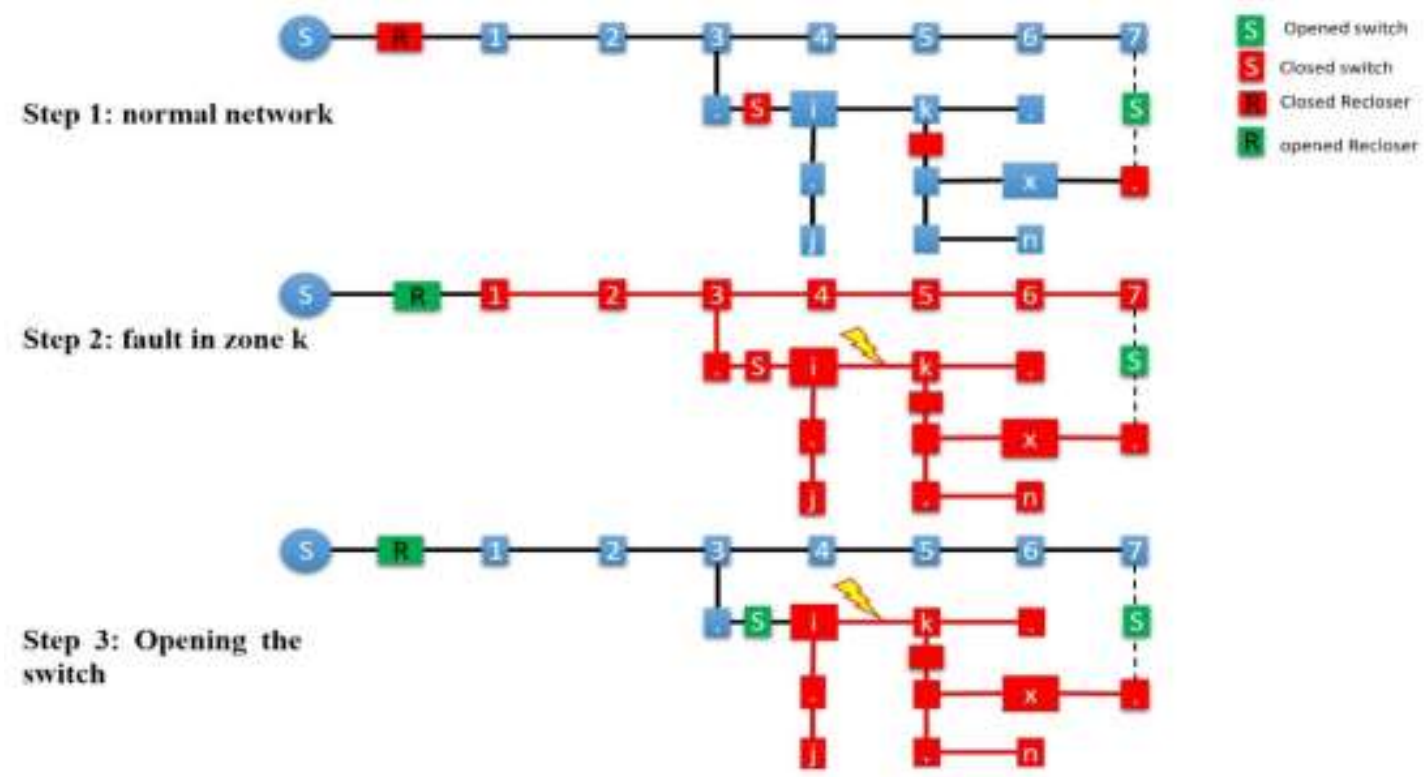

Figure 2. Technical coordination between the recloser and the switches to eliminate faults

In addition to these 3 steps, if there is an emergency zone and two switches between the fault zone and the emergency sources, these switches can change their states to restore a part of the network in order to improve reliability.

\subsubsection{Formulation of Reliability Indices}

The paper [2] proposed analytical assessment of reliability indices respecting the location of new type of recloser, remote controlled switches and the coordination between these equipment:

$$
\boldsymbol{f}\left(\boldsymbol{R}_{\boldsymbol{i}}, \boldsymbol{S}_{i}\right): S A I D I=\frac{\sum_{i=1}^{n} \sum_{j=1}^{n} \lambda_{i j} \cdot r_{i j} \cdot N_{i}}{\sum_{i=1}^{n} N_{i}} \boldsymbol{f}\left(\boldsymbol{R}_{\boldsymbol{i}}, \boldsymbol{S}_{i}\right): S A I F I=\frac{\sum_{i=1}^{n} \sum_{j=1}^{n} \lambda_{i j} \cdot N_{i}}{\sum_{i=1}^{n} N_{i}}
$$

The two parameters Ri, Si are position vectors of the reclosers, circuit breakers and remotecontrolled switches respectively. $\mathrm{Ri}=0$ means that a circuit breaker is installed in branch $\mathrm{i}$. Similarly, $\mathrm{Si}=0$ means that a remote-controlled switch is installed in branch $\mathrm{i}$.

\subsubsection{The Cost Function Formulation}

The sources of costs are related first of all to the price of the engineering and the equipment installed, including maintenance. Then the cost of the loss or the penalty for non-functioning of the system [26]. The first method to assess the outage is the macro method, which assesses the costs of interruption compared to the national economy [27]. The second type is the micro method. According to [27], during a 20-hour power outage for a Finnish household, the value of each minute of outage will be $0.78 €$. The same method is used in the article [28]. A shadow pricing study for energy reliability targeting in France suggests that a customer interruption has a shadow price of $€ 4.9$ of operational costs for rural regions, while it costs $7.5 €$ for urban areas. Other works formalize the cost compared to the unsupplied energy. A study carried out in Germany [29] using the VoLL methodology (value of loss of load) reported the following values: $€$ 7.41/kWh (Total); The paper [30] has shown that the estimated cost of failure of a business is at least 1.24 times to 1.3 times higher than a simple VoLL which includes the customer loss, because VoLL does not include indirect costs and the various damages suffered by businesses and customers during the power outage. In the rest of the work, we use the approximate values of interruption costs of 7.41 euro/kWh based 
on the VoLL method, multiplied by 1.3 since the estimated prices may be higher than the price announced by the VoLL method [30]. So the cost of outages in this document is $\mathrm{Co}=9,633$ euro/ $\mathrm{kWh}$.

The mathematical formulation of the cost function is based on the cumulative present value (CPV) method [16]. The idea of this method is that an investor would rather receive the fixed amount today that an equal amount in the future. The profit of the investment is the cost due to the improvement of the undistributed energy which evaluates the outage and the power losses [31].

$$
C P V(\mathrm{X})=\mathrm{X} * \frac{\left(1-a^{T}\right)}{(1-a)} \text { with } a=\frac{(1+i n f R)(1+L G R)}{(1+i n t R)} \text { and int } R=\text { the interest rate } ; L G R=
$$

the load growth rate; inf $R=$ the inflation rate;

$\mathrm{T}$ is the operational life of devices. In this study $\mathrm{T}=15$ years. The undistributed energy ENS is formalized respecting the following equation:

$$
E N S=\sum_{i=1}^{n} L_{i} \cdot \sum_{j=1}^{n} \lambda_{i j} \cdot r_{i j}
$$

The investment cost:

$\mathrm{INVCOST}=\mathrm{N}($ recloser $) *[\mathrm{C}($ recloser $)]+\mathrm{N}(\mathrm{RCS}) *[\mathrm{C}(\mathrm{RCS})]$

Maintenance cost:

$$
\begin{aligned}
& \operatorname{CPV}(\text { MAICOST })=\operatorname{MAICOST} \cdot \frac{\left(1-\mathrm{a}^{\mathrm{T}}\right)}{(1-\mathrm{a})} \\
& M A I C O S T=N(\text { recloser }) * \mathrm{mr} * C(\text { recloser })+N(R C S) * m r * C(R C S)
\end{aligned}
$$

$\mathrm{mr}$ : percentage annual rate of increase in the maintenance cost.the value of $\mathrm{mr}$ is presented in Table 1 .

Our work formalizes the cost function based on the CPV method used in several works. For example, the author in [31] maximizes the benefit by proposing a single-objective model. Knowing that our solution is multi-criteria and by addressing the loss cost function to minimize, therefore, the profit can be used to judge the results. The benefice function is the difference between the loss before and after the installation of reclosers and the remote-controlled switches. Using the above equations, the cost function to be minimized is formalized as follows:

$$
\text { Cost }=\text { ENS } * \operatorname{Co} * \frac{\left(1-\mathrm{a}^{\mathrm{T}}\right)}{(1-\mathrm{a})}+\operatorname{INVCOST}+\operatorname{MAICOST} * \frac{\left(1-\mathrm{a}^{\mathrm{T}}\right)}{(1-\mathrm{a})}
$$

The benefice of the solution is:

$$
B E N(\text { ENS }) * \operatorname{Ct} * \frac{\left(1-\mathrm{a}^{\mathrm{T}}\right)}{(1-\mathrm{a})}-\operatorname{INVCOST}-\operatorname{MAICOST} * \frac{\left(1-\mathrm{a}^{\mathrm{T}}\right)}{(1-\mathrm{a})}
$$

\subsubsection{Constraints}

Any optimization problem is subject to numerous constraints, these constraints complicate the result but also improve the solutions obtained, which allows the search algorithm to limit the search spaces and to orient it effectively towards the optimal solution:

- Only one recloser or switch can be installed on the same place.

- A recloser must be placed in the branch 1.

- $\quad$ Limitation of the maximum number of reclosers and switches.

\subsection{The Multi-Objective Problem-Solving Method}

It is very difficult to calculate the possible scenarios and the number of scenarios increases exponentially depending on the size of the network, which will increase the calculation time. This type of problem is very suitable for binary evolutionary techniques. In this article, we will use the NSGA2 algorithm to solve the problem. Concerning the genetic coding, a vector of dimension $2 \mathrm{~N}$ is used, with $\mathrm{N}$ the number of electric branches. This vector combines two vectors $\mathrm{R}$ and $\mathrm{S}$, the first vector represents the location of the research engine and the second one is used to code the location of the remote-controlled switches. A coding with 0,1 is used in each element of the vector, it represents the type of equipment, where 0 is a branch without equipment and 1 represents the location of the device. 
The flowchart in Figure 3 includes a mixing of 2 optimization techniques for multi-objective systems divided into 3 algorithms: (i) NSGA2; (ii) The weighting method based on entropy. (iii) The TOPSIS method for decision-making.

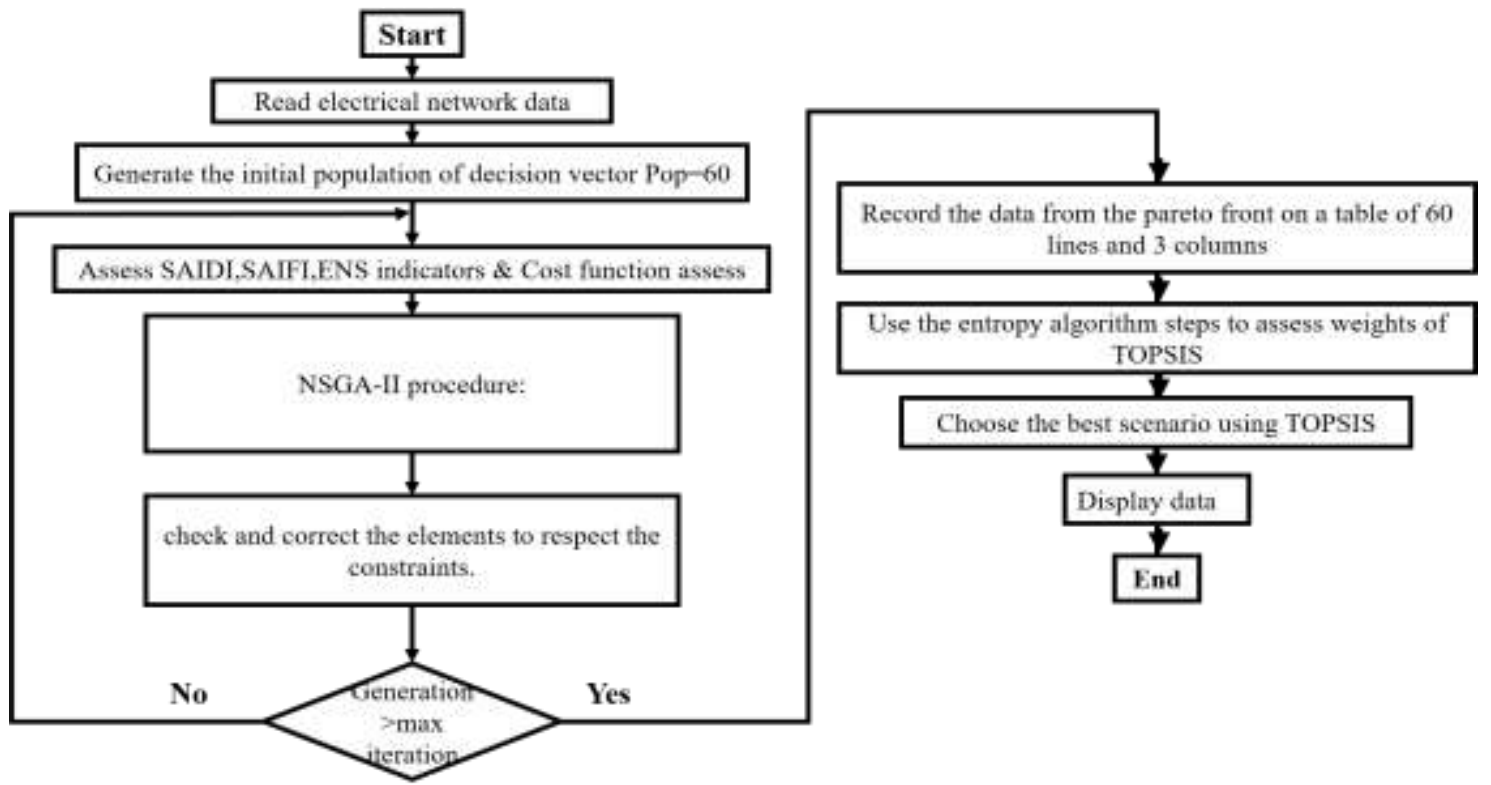

Figure 3. Flowchart of the problem-solving procedure

\subsubsection{Description of the problem-solving algorithm based on the genetic algorithm}

The genetic algorithm is a heuristic method for solving optimization problems. Its basic principle is the simulation of the survival of the fittest among individuals over generations of life. Each generation is a population coded as a chromosome and individuals must follow an evolutionary process according to several operators [25]. Guided by 5 basic operators:

1. Initial population production: the initial population is generated randomly based on the number of chromosomes in the decision vectors, the number of electrical connections in the distribution network in this work.

2. Evaluation of the objective function for each individual.

3. A loop is formed to generate a new population as a result.

(1) Selection:

(2) The crossover allows us to combine two elements selected from among the existing solutions by the selection operator.

(3) Mutation: The mutation operator allows us to randomly modify the chromosomes with a very low degree of probability. To introduce diversity at the population to escape the local optimum.

4. Transition to the next generation if the element respects the constraints.

5. End of the algorithm after the saturation of the conditions.

To overcome the limitation of the genetic algorithm in terms of manipulation of multiple objectives, the concept of Pareto front is introduced. Many multi-objective evolution algorithms have been exposed in recent years which work on this concept. One of these GA-based optimization methods is the Genetic Sorting algorithm - II (NSGA-II) [32].

Characterized by a non-dominated rapid sorting approach, a procedure for rapidly estimating crowding distance, the crowding distance comparison operator makes it possible to ensure the diversity of pareto-optimal solutions [33]. Elitism is introduced to allow the mother populations and their descendants to participate in the competition, thus reinforcing the convergence property of the optimization [34].

\subsubsection{Entropy Weighted Method}

The concept of entropy is a basic concept in thermodynamics then used in information theory in the form of Shannon's entropy concept [35]. Also known as the average amount of information, it can be used effectively in the decision-making process characterized by reliability and ease of use to obtain the criteria weights. The concept of entropy is well suited to measure the relative intensities of the ambiguity criteria in 
order to represent the average essential information transmitted for objective decision-making [36]. This objective weighting process is unbiased and capable of filling the gaps in subjective weighting methods [37]. Currently, the entropy-weighted method is applied in many research fields such as electrical energy, safety assessment [38], Tourism management [39]. The calculation steps [40] are detailed in Figure 4.

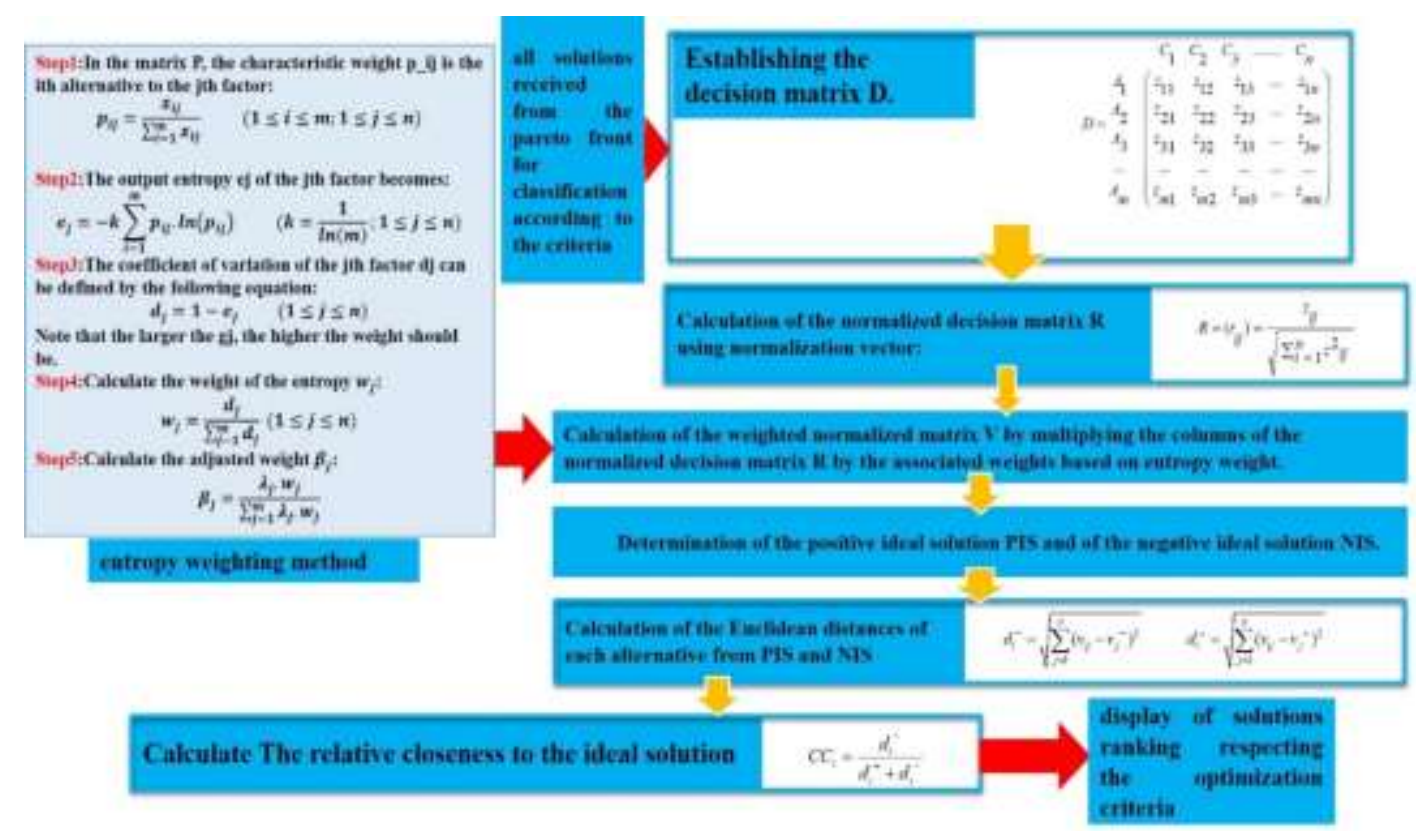

Figure 4. Entropy-TOPSIS method used for solving the problem

\subsubsection{TOPSIS Method}

TOPSIS is one of the multi-criteria mathematical decision-making methods, developed by Hwang and Yoon [41] and used to solve several optimization problems by classifying the scenarios of a multi-objective problem. Characterized by its simplicity and its computational efficiency, TOPSIS is perfectly adopted in many use cases. The basic principle of this algorithm is to classify the solutions on the basis of the idea that the best scenario must be very close to the ideal solution and far from being the negative ideal solution [42]. Decision objectives are taken into account according to weights which respond to the need for the optimization problem and help in decision-making. Several extensions of TOPSIS have been developed, in particular to assess the weight of the objectives. The general six-steps TOPSIS process is shown in [43] and presented in Figure 4.

\section{RESULTS AND DISCUSSION}

\subsection{Results based on NSGA2-entropyTOPSIS}

In this article, two IEEE 13 bus and 33 bus networks were selected to test the proposed algorithm using I7 VPro computer on matlab. Table 5 include data from the two networks, the Table 1 contain the economic data used to calculate the cost function. The reliability rates as well as the repair times for each zone are presented in Table 5 which will be useful for evaluating the reliability indices. (The test condition in Table 2 to 4 correspond to the limitation of the number of recloser and switches).

Table 1. System cost data

\begin{tabular}{cc}
\hline Device & Price (euros) \\
Recloser & 16500 \\
Remote-controlled switch & 9000 \\
\hline Parameter & Value in $\%$ \\
intR (the interest rate) & $10 \%$ \\
LGR (the load growth rate) & $5 \%$ \\
infR (the inflation rate) & $2 \%$ \\
mr & $5 \%$ \\
\hline
\end{tabular}


Table 2. Optimal indicator solutions

\begin{tabular}{cccccc}
\hline System & Constraints & SAIDI h/y & SAIFI F/y & Cost Mega euro & Calcultation time \\
\hline IEEE 13 bus & $\mathrm{R}=2$ and & 4.3904 & 1.5369 & 1.1166 & $13.6334 \mathrm{~s}$ \\
Reduction & $\mathrm{RCS}=6$ & $46 \%$ & $23 \%$ & $42 \%$ & \\
IEEE 33 bus & $\mathrm{R}=6 / \mathrm{RCS}=15$ & 5.1545 & 1.9676 & 3.8771 & $1 \mathrm{~min} 04 \mathrm{~s}$ \\
Reduction & & $\mathbf{7 3 \%}$ & $\mathbf{6 4 \%}$ & $\mathbf{7 5 \%}$ &
\end{tabular}

Table 3. Optimal location of devices

\begin{tabular}{ccc}
\hline System & Reclosers & Remote-controlled switches \\
\hline IEEE 13 bus & 1,8 & $4,6,7,10,11,13$ \\
IEEE 33 bus & $1 ; 7 ; 13 ; 19 ; 23 ; 26$ & $3 ; 4 ; 6 ; 8 ; 10 ; 12 ; 14 ; 16 ; 17 ; 21 ; 24 ; 25 ; 28 ; 3032$ \\
\hline
\end{tabular}

Table 4. Impact of limiting the number of devices on the optimization problem applied on IEEE33bus

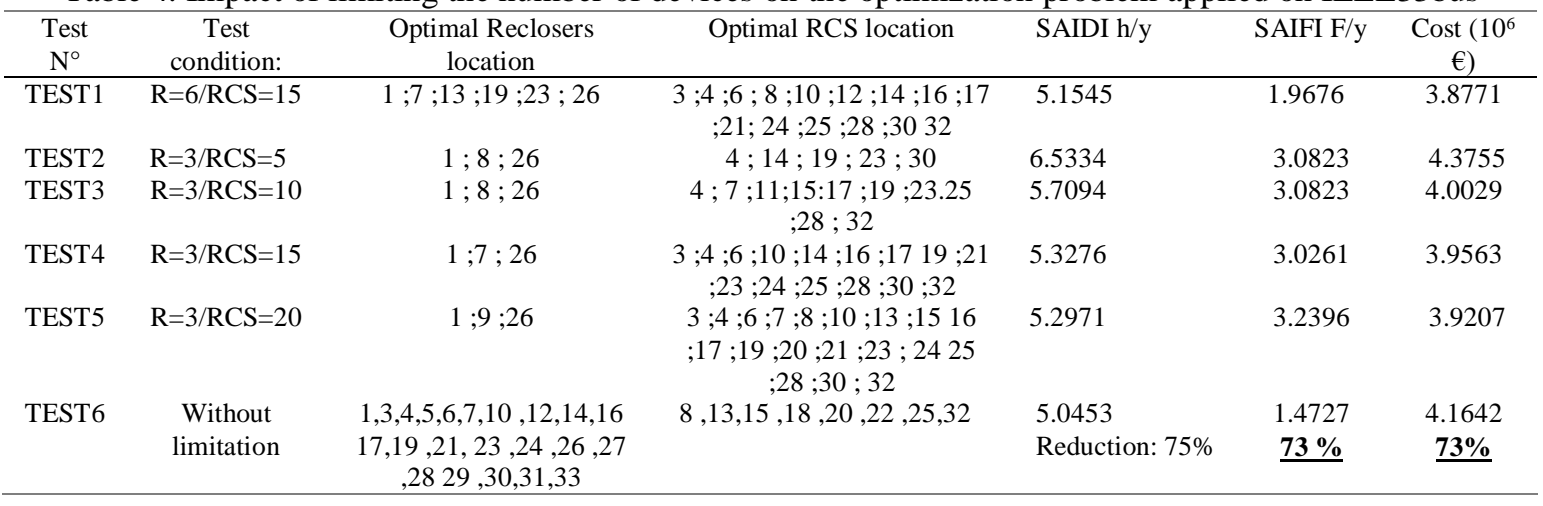

Table 5. IEEE 33BUS and IEEE13 BUS data

\begin{tabular}{|c|c|c|c|c|c|c|c|c|c|c|c|}
\hline Bus & $\mathrm{Li}(\mathrm{Kw})$ & $\begin{array}{c}\mathrm{N} \text { of } \\
\text { Custom } \\
\text { ers }\end{array}$ & $\begin{array}{l}\text { Fault } \\
\text { rate }\end{array}$ & $\begin{array}{c}\text { Repair } \\
\text { time (h) }\end{array}$ & $\begin{array}{l}\text { Isdßatsion } \\
\text { time (h) }\end{array}$ & Bus & $\mathrm{Li}$ & $\begin{array}{l}\mathrm{N} \text { of } \\
\text { custo } \\
\text { mers }\end{array}$ & $\begin{array}{l}\text { Fault } \\
\text { rate }\end{array}$ & $\begin{array}{c}\text { Repair } \\
\text { time }(h)\end{array}$ & $\begin{array}{l}\text { isolation } \\
\text { time }(\mathrm{h})\end{array}$ \\
\hline 1 & 0 & 0 & 0.1 & 2 & 0,1 & & & & & & \\
\hline 2 & 90 & 1 & 0.15 & 2 & 0,1 & 25 & 60 & 55 & 0.15 & 6 & 0,1 \\
\hline 3 & 120 & 55 & 0.25 & 3 & 0,1 & 26 & 60 & 80 & 0.15 & 4 & 0,1 \\
\hline 4 & 60 & 80 & 0.2 & 4 & 0,1 & 27 & 60 & 200 & 0.1 & 3 & 0,1 \\
\hline 5 & 60 & 200 & 0.1 & 4 & 0,1 & 28 & 120 & 47 & 0.25 & 4 & 0,1 \\
\hline 6 & 200 & 47 & 0.15 & 4 & 0,1 & 29 & 200 & 10 & 0.15 & 4 & 0,1 \\
\hline 7 & 200 & 10 & 0.1 & 3 & 0,1 & 30 & 150 & 4 & 0.15 & 3 & 0,1 \\
\hline 8 & 60 & 4 & 0.25 & 6 & 0,1 & 31 & 210 & 200 & 0.1 & 3 & 0,1 \\
\hline 9 & 60 & 200 & 0.1 & 6 & 0,1 & 32 & 60 & 10 & 0.2 & 3 & 0,1 \\
\hline 10 & 45 & 10 & 0.15 & 3 & 0,1 & 33 & 60 & 117 & 0.25 & 4 & 0.1 \\
\hline 11 & 60 & 117 & 0.25 & 4 & 0,1 & \multicolumn{6}{|c|}{ IEEE 13 BUS DATA } \\
\hline 12 & 60 & 145 & 0.20 & 2 & 0,1 & & & & & & \\
\hline 13 & 120 & 70 & 0.1 & 4 & 0,1 & 1 & 0 & 0 & 0,1 & 2 & 0.1 \\
\hline 14 & 60 & 55 & 0.15 & 3 & 0,1 & 2 & 90 & 0 & 0,15 & 4 & 0.1 \\
\hline 15 & 60 & 80 & 0.15 & 4 & 0,1 & 3 & 120 & 55 & 0,2 & 5 & 0.1 \\
\hline 16 & 60 & 200 & 0.2 & 6 & 0,1 & 4 & 60 & 80 & 0,25 & 6 & 0.1 \\
\hline 17 & 90 & 47 & 0.25 & 6 & 0,1 & 5 & 60 & 200 & 0,15 & 3 & 0.1 \\
\hline 18 & 90 & 10 & 0.1 & 4 & 0,1 & 6 & 200 & 47 & 0,1 & 2 & 0.1 \\
\hline 19 & 90 & 4 & 0.1 & 2 & 0,1 & 7 & 200 & 10 & 0,1 & 2 & 0.1 \\
\hline 20 & 90 & 200 & 0.25 & 4 & 0,1 & 8 & 60 & 4 & 0,15 & 4 & 0.1 \\
\hline 21 & 90 & 10 & 0.1 & 3 & 0,1 & 9 & 60 & 200 & 0,2 & 5 & 0.1 \\
\hline 22 & 90 & 117 & 0.2 & 4 & 0,1 & 10 & 45 & 10 & 0,25 & 6 & 0.1 \\
\hline 23 & 420 & 145 & 0.1 & 2 & 0,1 & 11 & 60 & 117 & 0,15 & 3 & 0.1 \\
\hline \multirow[t]{2}{*}{24} & 420 & 70 & 0.1 & 4 & 0,1 & 12 & 60 & 145 & 0,1 & 2 & 0.1 \\
\hline & & & & & & 13 & 120 & 70 & 0,1 & 2 & 0.1 \\
\hline
\end{tabular}

We note that the EntropyTOPSIS with fixed weight make possible to detect the best scenario by dectectiong two minimum objective (SAIDI and SAIFI), and without interest to fix the weight to avoid any subjectivity. The entropyTOPSIS solution optimizes reliability indices by making a financial benefit, which is the main objective of this work see the Table 6 . 


\begin{tabular}{ccccccc}
\hline & \multicolumn{4}{c}{ Table 6. Comparison between TOPSIS and entropyTOPSIS } \\
\hline System & method & Constraints & SAIDI h/y & SAIFI F/y & Cost Mega euro & Benefice 106euro \\
\hline IEEE 33 bus & TOPSIS & --- & 5.0841 & 1.5158 & $\mathbf{4 . 0 3 5 4}$ & 11.6542 \\
IEEE 33 bus & EntropyTOPSIS & --- & $\mathbf{5 . 0 4 7 5}$ & $\mathbf{1 . 4 9 0 2}$ & 4.1088 & 10.6423 \\
\hline
\end{tabular}

\subsection{Comparison of the Proposed NSGA2 with the Binary MOPSO Algorithm}

To show the efficiency of the proposed algorithm, the multi-objective NSGAII, presented in this paper, was compared to the multi-objective particle swarm optimization algorithm proposed in [18-21]. To adapt this algorithm to our problem, we used the binary variables as in [44]. We can see in Figure 5 that the elements in red representing the NSGAII algorithm give the Pareto front more quickly just after 80 iterations compared to the binary MOPSO the elements in blue in the figure. As mentioned in Table 7, the NSGAII algorithm can reach a better solution because it is more suited to the binary problem. Binary MOPSO also detects the optimal points identical to NSGA2, which validates the solution.

Table 7. Comparison between NSGA2 and binary MOPSO

\begin{tabular}{ccrcccc}
\hline Test $N^{\circ}$ & Test condition: & SAIDI h/y & SAIFI F/y & Cost Mega euro & Calcultation time & Iteration \\
\hline NSGA2 & no limitation & $\mathbf{5 . 0 4 7 5}$ & $\mathbf{1 . 4 9 0 2}$ & 4.1088 & $41.5416 \mathrm{~s}$ & 80 \\
MOPSO & no limitation & 5.0973 & 1.6477 & $\mathbf{4 . 1 0 8 2}$ & $142.1290 \mathrm{~s}$ & 180 \\
\hline
\end{tabular}

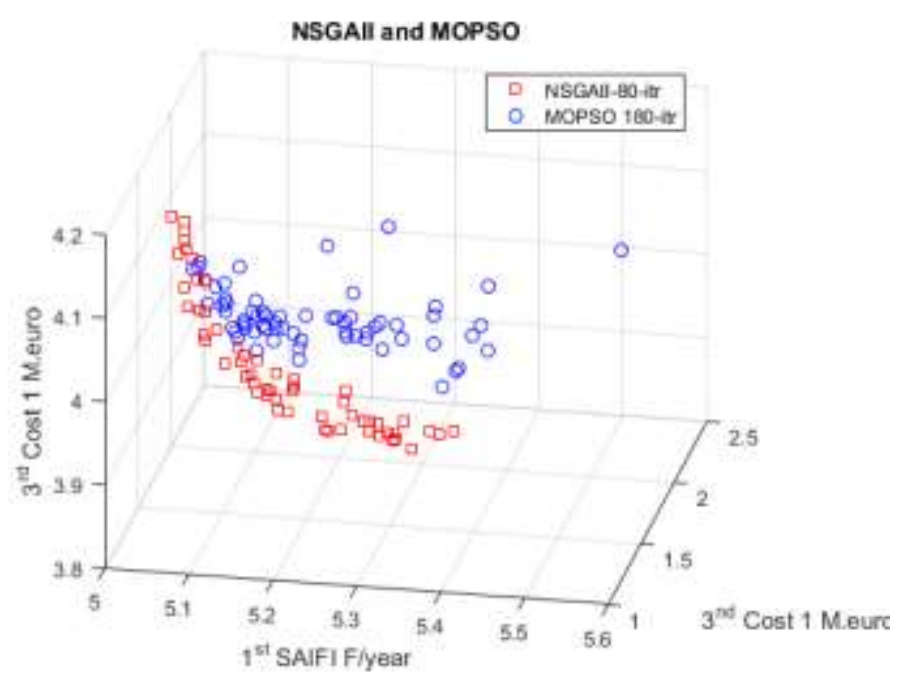

Figure 5. The Pareto front of the two methods MOPSO and NSGA2

\subsection{Discussion}

The best Pareto front obtained for the IEEE 33 bus network is illustrated in Figure 6, in this figure, a 3D graph is presented where each of the axes represents the SAIFI, the SAIDI, and the equipment and operating investment costs. By analyzing the 3D and 2D pareto front, we notice that the 60 populations are distributed over a surface according to the optimization criteria. The cost of the solution increases by minimizing the SAIDI and SAIFI indices. It is very difficult to choose the right solution directly from the pareto front, which validates the importance of applying the Entropy TOPSIS method for decision-making.TOPSIS does not require weight determination which avoids the risks of subjectivity during the decision making process.

The results obtained with the proposed method, for the IEEE 13 bus and the IEEE 33, were also compared with the results obtained without recloser and remote-controlled switches to assess the cost profile and reliability. The results are given in Table 2 and Table 3. As we can observe, the implementation of the recloser and remote-controlled switches effectively reduces the reliability indices to very significant values; $73 \%$ for SAIDI and $64 \%$ for SAIFI for this study by limiting the number of devices. Table 4 includes several tests by changing the number of available devices. We note that the benefit observed in terms of reliability has increased with the increase in the number of reclosers and RCS. In addition to reliability enhancement, the cost profit is saved, which leads the engineering networks utilities to invest in purchasing this type of equipment.The comparison of NSGA2 and binary MOPSO gives us the possibility of showing the efficiency 
of the genetic approach to this type of problem. We note that for both methods, the results are good. The calculation time of the proposed method shows that NSGA2 is more suited to this type of problem.

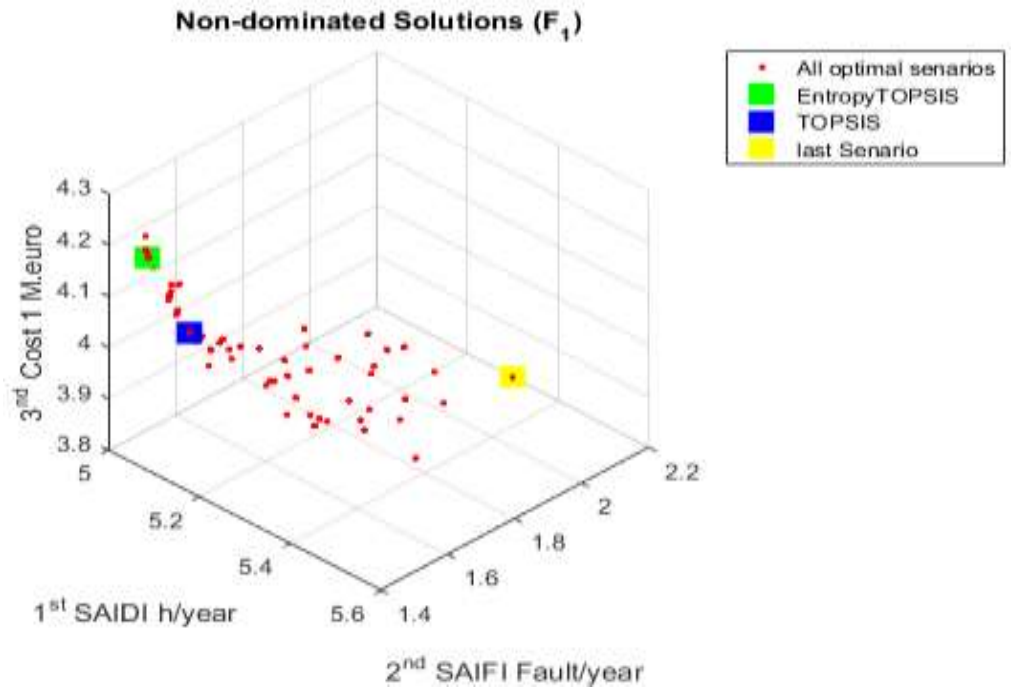

Figure 6. 3D Pareto front indicating the optimal scenario classified

\section{CONCLUSION}

This work establishes a mathematical model for the optimal placement of reclosers and switches in intelligent electrical distribution networks taking into account the principle of the automation and the coordination between these two intelligent devices. This correlation makes it possible to effectively reduce the reliability indices standardized by the IEEE Std $1366^{\mathrm{TM}}$ and frequently used to judge the performance of energy distributors. To obtain a more precise evaluation, this model uses an accurate objective function based on an analytical formulation to evaluate the reliability indices. In addition, a cost function is constructed as a function of the investment cost, the outage cost, and the maintenance cost. To solve this problem, method using the NSGA2 algorithm is proposed to determine the pareto front by manipulating the functional constraints of intelligent electrical networks. To choose the optimal solution, the TOPSIS entropy method is proposed to classify the pareto front solutions. This classification makes it possible to choose the optimal objective scenario which respects the tendencies of the energy distributors in an objective way.

\section{REFERENCES}

[1] S. R. Salkuti, "Challenges, issues and opportunities for the development of smart grid, International Journal of Electrical and Computer Engineering", International Journal of Electrical and Computer Engineering (IJECE), Vol.10, No.2, April 2020, pp. 1179-1186

[2] A.Lekbich, A.Belfqih, T.Ouderhman, J.Boukherouaa, F.Elmariami, "An analytical multicriteria model based on graph theory for reliability enhancement in distribution electrical networks", International Journal of Electrical and Computer Engineering (IJECE), Vol.9, No.6, December2019, pp. 4625 4636.

[3] M. Dragan, N. Srete, A. Emir, "Designing Automatic Meter Reading System Using Open Source Hardware and Software," International Journal of Electrical and Computer Engineering (IJECE), vol 7, no. 6, pp. 3282-3291, Dec 2017.

[4] A. Lekbich, A. Belfqih, C. Zedak ,J. Boukherouaa, F. Mariami, "A secure wireless control of Remote Terminal Unit using the Internet of Things in smart grid," 6th International Conference on Wireless Networks and Mobile Communications (WINCOM), 2018.

[5] N. Kulkarni, S.V.N.L. Lalitha, S. A. Deokar, "Real time control and monitoring of grid power systems using cloud computing", International Journal of Electrical and Computer Engineering (IJECE),Vol.9, No.2, April2019, pp. 941-949.

[6] C. Zedak, A.Lekbich, A.Belfqih, J.Boukherouaa, T.Haidi, F.El Mariami,“A proposed secure remote data acquisition architecture of photovoltaic systems based on the Internet of Things", 2018 6th International Conference on Multimedia Computing and Systems (ICMCS) 2018.

[7] A. Lekbich,A. Belfqih,T. Ouaderhman, J. Boukherouaa, C. Zedak, "A Remote Decentralized Reconfiguration Strategy of Smart Grid using the Internet of Things", 2019 Proceedings of 2019 IEEE World Conference on Complex Systems, WCCS 2019. 
[8] O.Feddaoui, R. Toufouti, L. Djamel, "Active and reactive power sharing in microgrid using droop control", International Journal of Electrical and Computer Engineering (IJECE), Vol.10, No.3, June 2020, pp. 2235- 2244.

[9] L.G.W. da Silva, R. A. F. Pereira, J. R.S. Mantovani,"Allocation of protective devices in distribution circuits using nonlinear programming models and genetic algorithms" Electric Power Systems Research 69 (2004) 77-84.

[10] G. Haifenga, A. Sohrab, "Parallel Monte Carlo simulation for reliability and cost evaluation of equipment and systems," Electr Power Syst Res,vol. 81, no. 2, pp. 347-56, 2011.

[11] J. H. Teng and Y. H. Liu, "A novel ACS-based optimum switch relocation method," IEEE Trans. Power Syst., vol. 18, no. 1, pp. 113-120, Feb. 2003.

[12] A.Moradi, M. F. Firuzabad, "Optimal Switch Placement in Distribution Systems Using Trinary Particle Swarm Optimization Algorithm”, IEEE Transactions on Power Delivery, Vol. 23, No. 1, January 2008.

[13] A. Abiri-Jahromi, M. Fotuhi-Firuzabad, M. Parvania, and M. Mosleh, ' Optimized sectionalizing switch placement strategy in distribution systems,'” IEEE Trans. Power Del., vol. 27, no. 1, pp. 362-370, Jan. 2012.

[14] Z. Popovic, B. Brbaklic, S. Knezevi , "A mixed integer linear programming based approach for optimal placement of different types of automation devices in distribution networks". Electric Power Systems Research 148 (2017) 136146.

[15] A. V. Pombo, J. M. Pina, V. F. Pires. "Multiobjective planning of distribution networks incorporating switches and protective devices using a memetic optimization". Reliability Engineering and System Safety 136 (2015) 101-108.

[16] S. Abdi, K. Afshar, S. Ahmadi, N. Bigdeli, M. Abdi. "Optimal recloser and autosectionalizer allocation in distribution networks using IPSO-Monte Carlo approach”. Electrical Power and Energy Systems 55 (2014) 602611.

[17] IEEE Power Engineering Society, IEEE Std. 1366:-2003 IEEE Guide for Electric Power Distribution Reliability Indices, Institute of Electrical and Electronics Engineers, Inc., New York, 2004, p. 35, May 14.

[18] H. R.Baghaee, M.Mirsalim,G. B.Gharehpetian,"Multi-objective optimal power management and sizing of a reliable wind/PV microgrid with hydrogen energy storage using MOPSO". Journal of Intelligent \& Fuzzy Systems, Vol 32(3), 1753-1773, 2017.

[19] H. R.Baghaee, M. Mirsalim, G. B. Gharehpetian, A. K.Kaviani,"Security/cost-based optimal allocation of multi-type FACTS devices using multi-objective particle swarm optimization", SIMULATION, Vol 88(8), 999-1010, 2012.

[20] H. R. Baghaee, M. Mirsalim,G. B.Gharehpetian, H. A.Talebi,"Reliability/cost-based multi-objective Pareto optimal design of stand-alone wind/PV/FC generation microgrid system", Energy, 115, 1022-1041,2016.

[21] H.R.Baghaee1, M.Mirsalim, G.B. Gharehpetian, H.A. Talebi1,"MOPSO/FDMT-based Pareto-optimal solution for coordination of overcurrent relays in interconnected networks and multi-DER microgrids", IET Gener. Transm. Distrib., 2018, Vol. 12 Iss. 12, pp. 2871-2886

[22] S. Ghasemi. "Balanced and unbalanced distribution networks reconfiguration considering reliability indices". Ain Shams Engineering Journal Volume 9, Issue 4, December 2018, Pages 1567-1579

[23] S. Küfeoglu, M. Lehtonen. "Macroeconomic Assessment of Voltage Sags”. Sustainability 2016, 8, 1304.

[24] R. Billinton, R.N. Allan, “ Reliability Evaluation of Power System”, Plenum Press, New York 1998.

[25] S. Ray, S. Bhattacharjee ,A. Bhattacharya. "Optimal allocation of remote control switches inradial distribution network for reliabilityimprovement”. Ain Shams Engineering Journal 9,403-414, 2018.

[26] S. Küfeoglu,M. Lehtonen,"Interruption costs of service sector electricity customers, a hybrid approach", International Journal of Electrical Power \& Energy Systems, Volume 64, Pages 588-595, January 2015.

[27] S. Küfeoglu, N. Gündüz, H. Chenand M. Lehtonen. "Shadow Pricing of Electric Power Interruptions for Distribution System Operators in Finland". Energies 2018, 11, 1831; doi:10.3390/en11071831.

[28] T.J. Coelli, A. Gautier, S. Perelman, R. Saplacan-Pop, "Estimating the cost of improving quality in electricity distribution: A parametric distance function approach", Energy Policy 2013, 53, 287-297.

[29] C. Growitsch, R. Malischeck, S. Nick, H. Wetzel, "The cost of power interruptions in Germany: a regional and sectoral analysis". Ger. Econ. Rev. 13 (3), 307-323, 2014.

[30] K. Kim, Y. Cho. "Estimation of power outage costs in the industrial sector of South Korea". Energy Policy 101 (2017) 236-245

[31] A.Alam, V. Pant, B. Das,"Switch and recloser placement in distribution system considering uncertainties in loads, failure rates and repair rates", Electric Power Systems Research, Volume 140, November 2016, Pages 619-630

[32] P. C. Ramaswamy, G. Deconinck. "Smart Grid Reconfiguration Using Simple Genetic Algorithm and NSGA-II", 3rd IEEE PES Innovative Smart Grid Technologies Europe (ISGT Europe), Berlin, 2012.

[33] K. Deb, A. Pratap,S. Agarwal, T. Meyarivan. "A fast and elitist multiobjective genetic algorithm: NSGA-II", IEEE Trans Evol Comput 2002;6(2):182-97.

[34] K. Deb, "Multi-Objective Optimization Using Evolutionary Algorithms”, Wiley, Singapore, 2001.

[35] C. Shannon, “ A mathematical theory of communication”. Bell Syst Tech J 1948; 27:379e423.

[36] M. Zeleny, "Multiple Criteria Decision Making”. Springer, New York 1996.

[37] B. Srdjevic, Y.D.P Medeiros ,A. S Faria AS, “An objective multi-criteria evaluation of water management scenarios. Water", Resources Management 18(1):35-54.

[38] L.I. Xiangxin ,K. WANG ,L. LIU ,J. XIN , H. YANG,C. GAO, “Application of the Entropy Weight and TOPSIS Method in Safety Evaluation of Coal Mines", Procedia Engineering 26 (2011) 2085 - 2091

[39] H.Zhang, C. Gu, L.Gu, Y.Zhang, "The evaluation of tourism destination competitiveness by TOPSIS \& information entropy e A case in the Yangtze River Delta of China", Tourism Management 32 (2011) 443-451

[40] A. Konaka ,D. W. Coitb, Al. E. Smith ."Multi-objective optimization using genetic algorithms: A tutorial". Reliability Engineering and System Safety 91 (2006) 992-1007 
[41] B. M. D. Santos, L. P. Godoy, L. M.S. Campos, "Performance Evaluation of Green Suppliers using EntropyTOPSIS-F”, Journal of Cleaner Production (2018), doi: 10.1016/j.jclepro.2018.09.235

[42] C. L Hwang, K. Yoon, "Multiple attribute decision making:methods and applications a state-of-the-art survey", Springer Science \& Business Media, Vol. 186,2012.

[43] A.Lekbich, A.Belfqih, T.Ouaderhman, J.Boukherouaa, C.Zedak. "A Remote Decentralized Reconfiguration Strategy of Smart Grid using the Internet of Things", 2019 4th World Conference on Complex Systems (WCCS), 12 December 2019,10.1109/ICoCS.2019.8930729

[44] W. Bin, P. Qinke, Z. ing, C. Xiao, "A binary particle swarm optimization algorithm inspired by multi-level organizational learning behavior", European Journal of Operational Research, Volume 219, Issue 2, 1 June 2012, Pages 224-233

\section{BIOGRAPHIES OF AUTHORS}

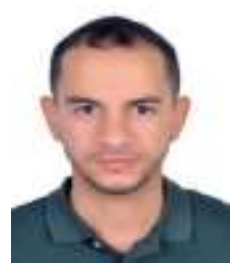

Anass Lekbich: PhD student at the National School of Electricity and Mechanics (ENSEM Hassan II University of Casablanca), was born in Morocco on the 19th of November 1988. He got his Eng. Degree from ENSEM - Hassan II University of Casablanca, in 2012. He has more than 8 years of professional experience in the industry, as automation and networks engineer with experience in research. He has carried out several research projects on the reliability of the electrical distribution networks, the control of the power systems, the optimization of distribution networks and the location of the protective equipment. His research interests include electrical networks, distribution systems, reclosers and switches placement, SCADA system, The remote control of electrical networks and smart grids.

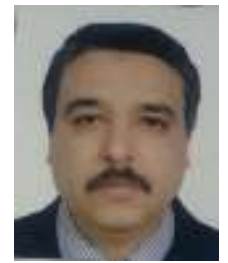

Pr. Abdelaziz Belfqih: Professor qualified to Direct Research at the National School of Electricity and Mechanics (ENSEM - Hassan II University of Casablanca). Doctor, Engineer and holder of the University Habilitation HDR. RECS Research Team Leader. Currently working on Electrical networks.

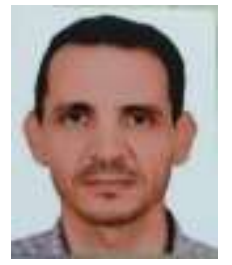

Pr. Tayeb Ouaderhman: Assistant professor at Hassan 1 University of Settat morocco. $\mathrm{PhD}$ on Operation research. Actually, working on multicriteria decision making and machine learning. Email: tayeb.ouaderhman@usms.ac.ma

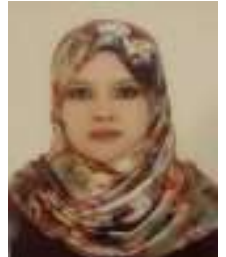

Chaimae Zedak: PhD student at the National Higher School of Electricity and Mechanics (ENSEM - Hassan II University of Casablanca). She got his Engineering Degree in electrical engineering, electronics and telecommunications, from ENSEM - Hassan II University of Casablanca, in 2016. Her research interests include the optimization and management of electrical distribution systems, the location of renewable energies, energy management and remote monitoring and control of electrical distribution networks in the presence of renewable sources.

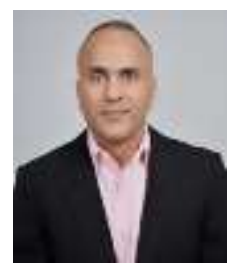

Pr. Jamal Boukherouaa: Professor qualified to Direct Research at the National School of Electricity and Mechanics (ENSEM - Hassan II University of Casablanca). Doctor, Engineer and holder of the University Habilitation HDR. RECS Research Team Leader. Currently working on high-frequency static converters.

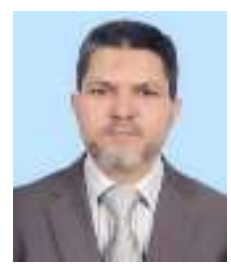

Pr. Faissal El Mariami: Professor qualified to Direct Research at the National School of Electricity and Mechanics (ENSEM - Hassan II University of Casablanca). Doctor, Engineer and holder of the University Habilitation HDR. RECS Research Team Leader. Currently working on location of FACTS in Electrical networks. 